\title{
UM NOVO CASO DE QUALIFICATIVA PENAL EM HOMICEDIO
}

\author{
Ary Florencio Guimarães
}

\author{
(Professor da Faculdade de Direito de Curitiba, \\ membro do Conselho Penitenciário e 1.0 Sub-Pro- \\ curador Geral do Estado.)
}

1. A matéria constante da proposição pode ser assim resumida:

“O assassínio de mulher grávida deve constituir, no sistema adotado pelo Código Penal B́rasileiro, circunstância qualificativa do crime de homicídio, desde que o agente conheça a gravidez da ofendida ou seja notório êsse estado". (*)

A mulher-gestante deve merecer cuidados especiais por parte do Estado.

Ela é o receptáculo sagrado do ser humano, que possué direitos inauferíveis e inalienáveis no seio da família e da sociedade em geral.

(*) Indicação apresentada ao $10^{\circ}$ Congresso do Ministério Público do Ceará, realizado em Fortaleza no mês de dezembro de 1953, e aprovada por unanimidade de votos. 
A pessoa natural é protegida pelo organismo estatal desde a sua concepção até à morte.

Daí a punibilidade do abôrto, que é a extinção de um ente em formação e que se irá completar pelo nascimento com vida; daí as normas do direito sucessório e as que regem as disposições de última vontade.

Proteger, assim, a mulher em estado de gestação, representa dever indeclinável da organização sócio-jurídica da sociedade, de que o Estado, por seus órgãos e no desempenho de suas altas e generosas finalidades para atingir o bem comum, é o titular e o mais autorizado e categorizado guardião.

A família, todos sabemos e nunca é ocioso repetir, é a célula natural e fundamental da sociedade, e nela a mulher-gestante ocupa, não há dúvida, o centro catalizador das mais intensas e profundas virtualidades.

0 direito à proteção da maternidade, como corolário daquele outro direito essencial inerente à personalidade humana - o direito à vida —, representa, hoje em dia, uma das mais nobres e alevantadas declarações ligadas à pessoa humana. A ORGANIZAÇÃO DAS NAÇõES UNIDAS (ONU), na sua já famosa Carta Universal dos Direitos do Homem, conforme - texto aprovado pela sessão plenária da Assembléia Gerał a 6 de dezembro de 1948, inscreveu, depois de consignar que " $a$ família é o elemento natural e fundamental da sociedade e tem direito à proteção da Sociedade e do Estado" (artigo 16, item 3), e proclamou solenemente que " $a$ Maternidade e a Infância têm direto a cuidados e assistência especiais" (artigo 25, item 2).

Declara a Constituição Federal, por sua vez, que a família, constituída pelo casamento de vínculo indissolúvel, "terá direito à proteção especial do Estado", devendo ser obrigatòriamente exercitada, em todo o território nacional, a assistência à maternidade. $\mathrm{E}$, na parte concernente às relações de trabalho, consagra ainda o nosso Magno Estatuto, de modo específico, o relevante direito, que corresponde à gestante, de usufruir "descanso antes e depois do parto, sem prejuizo do emprêgo nem do salário” (cf. arts. 163, 164 e 157, n. ${ }^{\circ} \mathrm{X}$ ). 
2. Vejamos, agora, no campo mais pròpriamente jurídico, a justificação do nosso alvitre.

O Código Penal Brasileiro, no seu art. 129, quando cogita das lesões corporais qualificadas pelo resultado, prevê, dentre outras, as hipóteses de que resultem a aceleração do parto ou o abôrto.

Com efeito, estabelece o mencionado dispositivo:

"Ofender a integridade corporal ou a saúde de outrem:

$\S 1 .^{\circ}$ - Se resulta :

$I-\ldots \ldots \ldots \ldots \ldots \ldots \ldots \ldots \ldots \ldots \ldots \ldots \ldots \ldots$

$\mathrm{II}-\ldots \ldots \ldots \ldots \ldots \ldots \ldots \ldots$

III $-\ldots \ldots \ldots \ldots \ldots \ldots$

IV - aceleração do parto:

Pena - reclusão, de um a cinco anos.

$\S 2 .^{\circ}-$ Se resulta :

$I-\ldots \ldots \ldots \ldots \ldots \ldots \ldots \ldots$

$\mathrm{II}-\ldots \ldots \ldots \ldots \ldots \ldots$

III $-\ldots \ldots \ldots \ldots \ldots \ldots \ldots \ldots \ldots$

IV $-\ldots \ldots \ldots \ldots \ldots \ldots \ldots \ldots$

V. - abôrto:

Pena - reclusão, de dois a oito anos".

3 - Trata-se, aí, sem dúvida, de dois casos típicos das chamadas lesões corporais qualificadas pelo resultado.

$O$ crime, no entanto, como esclarece NELSON HUNGRIA, "apresenta-se com pena diversa da ordinária, mas não há mudança de nomen juris. Os resultados, enumerados nos referidos parágrafos, funcionam como agravantes especiais ou condições de maior punibilidade, e não como elementos constitutivos de crime distinto". (In "Comentários ao Código Penal”, vol. V, pág. 288).

4 - A aceleração do parto configura, assim, no sistema do estatuto penal em vigor, uma lesão grave. Caracteriza-se "pela expulsão precoce do produto da concepção, mas em tal estado de maturidade, que pode continuar a viver fora do útero ma- 
terno. Compreende tanto o caso em que o parto advém antes do tempo normal (mas necessàriamente depois do tempo mínimo para a possibilidade da vida extra-uterina), quanto o caso em que ocorre no tempo normal, mas por trauma físico ou psíquico. Pressupõe-se que o feto esteja vivo, nasça vivo e continue a viver, dado o seu gräu de maturação. Se o feto morre no útero ou fora dêle, em conseqüência da lesão, o fato passa a ser abôrto, e a lesão se qualificará como gravíssima $\left(\S 2 .^{\circ}, \mathrm{n} .^{\circ} \mathrm{V}\right.$, do art. 129)", consoante a lição de HUNGRIA. (Op. cit., pág. 295).

5 - O Código considera, por outro lado, como lesão gravíssima, como já foi dito, a que ocasiona o abôrto, inscrito êste como ofensa à vida desde a legislação imperial até os nossos dias.

"O evento abôrto, para a existência da agravante especial", - o ensinamento ainda nos é ministrado pelo insígne tratadista, - "não deve ter sido, de qualquer forma, querido pelo agente, pois, do contrário, terá êste de responder por dois crimes em concurso (o da lesão e o do abôrto) ou por abôrto qualificado (se a lesão, per se, fôr grave). Há que dịstinguir entre a hipótese do inciso $\mathrm{V}$ do $\S 20^{\circ}$ do art. 129 e a do art. 127, primeira parte, pois há uma inversão de situações: na primeira a lesão é querida e o abôrto, não; na segunda, o abôrto é que é o resultado visado, enquanto a lesão não é querida, nem mesmo eventualmente. Se o agente ignora a gravidez da ofendida e não tinha razão alguma para conhecê-la, a solução deve ser idêntica à que já formulámos no caso de lesão de que resulte aceleração de parto: o agente, tendo incidido em insuperável êrro de fato, não deve responder por lesão qualificada pelo resultado "abôrto". (Obra citada, pág. 301).

6 - Magistrais, na verdade, os conceitos expendidos pelo consagrado e emérito penalista, no tocante à apreciação do sistema adotado pelo legislador do nosso Código em relação às lesões corporais.

7 - Mas, pergunta-se: 
O autor de homicídio contra mulher grávida, isto é, aquele que extingue, violenta e sanguinàriamente, não só uma vida já formada e uma realidade orgânica e social da mais alta valia no seio da comunidade (a ofendida-mãe), como também uma vida em formação, uma pessoa em formação (MANZINI), o feto dentro do ventre materno, o nascituro que é protegido pela lei civil desde o momento mesmo de sua concepção (Código Civil, art. $4 .^{\circ}$, e Cód. de Proc. Civil, art. $\left.600, \S 1 .^{\circ}\right)$, êsse homicida, revelador de altíssimo grāu de periculosidade, não deveria, por igual, ter o seu ato, sumamente criminoso, inscrito em a lei positiva penal na categoria de crime qualificado por êsse resultado duplamente danoso à sociedade e à ordem jurídica, e punido, conseqüentemente, com a pena mais elevada de 12 a 30 anos?

Assim evidentemente, deveria estapelecer a lei!

A norma legal, porém, não permite tal solução, por isso que as agravantes que qualificam o crime de homicídio, como é sabido, são, tão sòmente, as enumeradas nos incisos do $\S 2 .^{\circ}$ do art. 121 do Código Penal, isto é, se o crime fôr cometido: I - mediante paga ou promessa de recompensa, ou por outro motivo tôrpe; II - por motivo fútil; III - com emprêgo de veneno, fôgo, explosivo, asfixia, tortura ou outro meio insidioso ou cruel, ou de que possa resultar perigo comum; IV - à traição, de emboscada, ou mediante dissimulação ou outro recurso que difieulte ou torne impossível a defesa do ofendido; e V - para assegurar a execução, a ocultação, a impunidade ou vantagem de outro crime.

Em suma : o crime menos grave - o de lesões corporais é qualificado pelos resultados "aceleração do parto" ou "abôrto"; enquanto o homicídio - delito máximo contra a vida e, no caso, contra duas entidades humanas - e que é, no dizer de HUNGRIA, "o tipo central dos crimes contra a vida e é o ponto culminante da orografia dos crimes, o crime por excelência, o padrão da delinqüência violenta ou sanguinária, que representa como que uma reversão atávica às eras primevas, em que a luta pela vida, presumivelmente, se operava com o uso normal dos meios brutais e animalescos. $\mathrm{E}$ mais chocante violação do 
senso moral médio da humanidade civilizada" (op. cit. pág. 23), - o homicídio, como diziámos, praticado contra a mulher em estado de gestação, não é considerado, contraditòriamente, pelo Código, como delito qualificado...

Esse tratamento diverso da lei penal em vigor, como se vê, não merece encômios e se nos afigura desajustado do próprio sistema adotado pelo legislador, de maneira gritante e injustificável!

E a única maneira de contornar a situação, à vista da rigidez do sistema delineado (afastada a hipótese de concurso entre o homicídio e o abôrto), é a de, num determinado caso concreto, levar-se em consideração o duplo e irreparável resultado danoso do evento, para fazê-lo funcionar contra o horroroso matador de dois seres humanos, não como circunstância qualificativa do crime de homicídio, mas, apenas, como agravante de caráter judicial, entregue ao exame do juiz para a individualização da pena, segundo as regras constantes do art. 42 do Código Penal.

Este conclave, de tão oportuno significado para o aprimoramento da ordem jurídica no país, não pode, nem deve, a nosso ver, ficar ausente do aspecto focalizado nesta ligeira e despretenciosa indicação, procurando, como é do seu objetivo, equacionar solução compatível com as exigências das realidades surgidas no pretório da justiça repressiva, para bem informar a política criminal brasileira.

A vista do exposto, e confiantes nos esclarecimentos e suprimentos da cultura profissional dos integrantes do I Congresso do Ministério Público do Ceará, propomos ou indicamos seja a matéria devidamente considerada pelo plenário, para o efeito de se sugerir, acaso aprovada esta indicação, a conveniência de 
se incluir, desde logo, por meio de lei especial modificadora do Código Penal, na parte referente às-qualificativas do crime de homicídio (a hipótese poderia compor, v.g., o sexto inciso da discriminação do $\S 20^{\circ}$ do art. 121), ou, então, futuramente, quando da elaboração de um novo diploma penal, a circunstância que determine a majoração quantitativa da pena (de 12 a 30 anos), desde que resulte da ação ou da omissão a destruição do feto, conhecendo o agente a gravidez da ofendida, ou, mesmo, quando seja notório êsse estado. 